\title{
Manufacturing of Humidification Chamber Bottom Plate for Fuel Cell with HDPE Composite Injection Molding
}

\author{
Rangaswamy $\mathrm{T}^{1}$ and Yogesha S. A. ${ }^{2}$
}

\begin{abstract}
Humidifier is a component of fuel cell power stack in fuel cell bus which is used to hydrate the membrane of bi-polar plate. Initially it is designed with aluminium which weighs around 10 kilograms. As the power to weight ratio is an important consideration in any automobile design, reduction of weight of the bus increases power. Hence, the weight of the humidifier is to be reduced by using possible composite materials and at the same time it should satisfy the working conditions as Aluminum.
\end{abstract}

Keywords-Fuel cell, Humidification, Composite material, Moulding techniques.

\section{INTRODUCTION AND WORKING PRINCIPLE}

$\mathrm{P}$ OLYMER electrolyte membrane (PEM) fuel cells have the ability to operate at very low temperatures; this is the main attraction of the PEM. Since they have the ability to deliver such high power densities at this temperature they can be made smaller which reduces overall weight, cost to produce and specific volume.

Reactants are humidified to keep polymer membrane of polymer electrolyte fuel cell stack wet and saturated with water for sustained ionic conductivity. Air module of fuel cell power system comprises of air compressor and humidifier which maintain adequate flow of air and maintain the pressure of system to keep the membrane saturated with water vapour. Air after compression becomes hot and need to be cooled and humidified. This cooling and humidification in the air inlet manifold where in hot air is allowed interact with porous matrix soaked with water. Porosity matrix is chosen so that there is pressure drop across the manifold. Air cools below prescribed limit and get humidified and allowed to pass through plate heat exchanger and allowed to equilibrate with fluid emerges out of thermal management system which acts either as heat sink and heat sources and condition the air and maintain the temperature of air to prescribed limit. Temperature of air at the air inlet manifold after interaction with water in the glass matrix may be more than or lower than stack temperature which depends on the ambient humidity and temperatures. If the temperature of air more than the stack temperature, air cooled to recommended level in the plate exchanger module by means of equilibrating with coolant maintained at prescribed temperature.

${ }^{1}$ Professor, Dept. of Mechanical Engineering, Government Engineering College, Hassan, KA, INDIA

${ }^{2}$ Manager, TATA Motors Research Centre, Bengaluru, KA, INDIA E-mail: ${ }^{1}$ tr@gechassan.ac.in, 2yogesha.sa@tatamotors.com
Heats released by air compressor due to inefficiency in the compression process and fuel cell stack is used for air humidification and conditioning. Similarly from hydrogen storage containers is regulated and passed through humidifier and conditioned prior to feeding into stack. Heat released by fuel cell stack is used for humidification of hydrogen. Coolant circuits of hydrogen and air humidifiers are integrated. Humidity is also controlled by controlling and regulation of water flow into the air inlet manifold by means of using water dosing pump with variable speed dirve and controller which is taking humidity as input.

\section{LITERATURE REVIEW}

Fuel cell powered hybrid vehicles (FCHV) have demonstrated as an alternative solution that could potentially replace the current Internal Combustion Engine (ICE) based propulsion system because of depletion of the fossil fuels and the associated emissions. Dongmei Chen et al [1] (2004) modeled a membrane humidifier for automotive fuel cell systems they found that by controlling the number of humidification cell units, one can actively control the fuel cell inlet air to maintain proper membrane humidification for the fuel cell stack. David O. Kazmer et al [2] (1997) proposed PIM technology of next generation he found that computer integrated injection moulding used for critical shape high dense polyethylene materials. S M Tamboli et al [3] (2003) did research on Cross-linked polyethylene and found that forms a dense network of high molecular weight, which improves impact strength, environmental stress crack resistance (ESCR), softening point, creep and abrasion resistance without influencing tensile strength and density to any appreciable extent. The advantages of crosslinking HDPE and different properties like vicat softening point and yield stress are studied.

\section{MATH}

Material selection plays an important role as the humidifier has to deal with a pressure of 2 Bar and temperature ranging from ambient to $90 \mathrm{oC}$ (maximum) and have to bare a load of 80 Newton. Simultaneously it should be lighter than aluminum and should be cheaper and fabricating time should be less and it should be capable of mass production and before all this it should serve the purpose. When developing 
plastic parts. Selection of an appropriate plastic material is vital in product development since the properties of the plastic are closely tied not only to the product design but also to the mold designs and process optimization. Inappropriate material selection may incur severe costs and delays late in the product development cycle (related to trying different materials and product redesigns. Material selction id based on many considerations like mechanical properties, thermal properties,processing properties.

\subsection{Polymer Electrolyte Membrane(PEM) Fuel Cell}

Polymer electrolyte membrane fuel cells have the ability to operate at very low temperatures. Since they have the ability to deliver such high power densities at this temperature they can be made smaller which reduces overall weight, cost to produce and specific volume. Since the PEM has an immobilized electrolyte membrane there is simplification in the production process that in turn reduces corrosion, this provides for longer stack life [4].

\subsection{Polyethylene}

Polyethylene (PE) is a thermoplastic polymer consisting of long chains produced by combination of the monomer molecules viz. ethylene. Depending on the mode of polymerization, three basic types of polyethylene are frequently used: linear High-Density Polyethylene (HDPE), and Linear Low-Density Polyethylene (LLDPE), Low Density Polyethylene (LDPE). HDPE has a low degree of branching and thus greater intermolecular forces and tensile strength. It can be produced by chromium/ silica catalysts, Ziegler-Natta catalysts or metallocene catalysts. HDPE is used in products such as home appliances, milk jugs, detergent bottles, margarine tubs, garbage containers, toys and water pipes, in packaging and in automotive applications.

\subsection{Process Selection}

Once the determination has been made regarding the use of plastic for a part design, the next most important decision is likely the selection of the manufacturing process. While there are many types of plastics manufacturing systems [5], four of the most common are extrusion, injection molding, blow molding, and thermoforming. Together with roto- molding, these five plastics conversion processes accounted for sales in the United States of over 94 billion dollars in 2007 [6]; global sales of plastics products is several multi- ples higher [7].

\subsection{Method of Joining Bottom Plate And Humidifier Core}

Bottom plate which is fabricated with XLPE has to be joined to core and core has to be joined to top plate in aluminium prototype these are joined by arc welding process but when polyethylene is used arc welding cannot be done instead induction welding can be carried out.

\subsection{Induction Welding}

Using the principles of inductive heating to create fusion temperatures in a joint area, electromagnetic welding creates excellent hermetic or high-pressure seals. This process requires bonding material, usually supplied as extruded profiles such as strands (beads), tape or sheet, or special injection-moulded profiles conforming to a particular joint contour.

\subsection{Cross Linking Through Infrared-Radiation}

Crosslinking is a process in which carbon atoms of same or different polyethylene chains are joined together to form the three-dimensional network structure14-16. The crosslinking process essentially forms bonds between the polymer chains, which could be directly between carbon to carbon or a chemical bridge linking two or more carbon atoms. The main difference between thermoplastic and cross linked polymer is that, at temperature above the crystalline melting point cross linked polymer behaves as a soft rubber while thermoplastic has no significant strength above melting temperature. The changes in the properties of polyethylene due to crosslinking have been compared and documented in literatures [8] \& [9]. Thus, crosslinking reduces the melt index and elongation at break, while improves the impact strength, creep resistance, resistance to slow crack growth and also environmental stress crack resistance (ESCR) [5]. Cross linking incorporates strong intermolecular bonding. After crosslinking tensile modulus will be increased a little and enhanced performance at higher temperatures Annealing of cross-linked polymer is done which increases tensile modulus further and internal stresses will be relived if any.

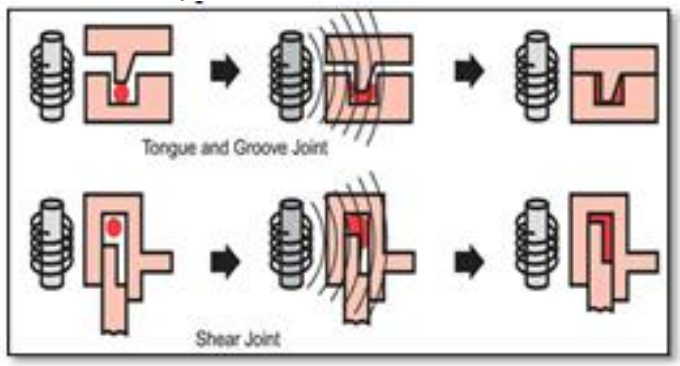

Fig. 3.6a: Induction Welding

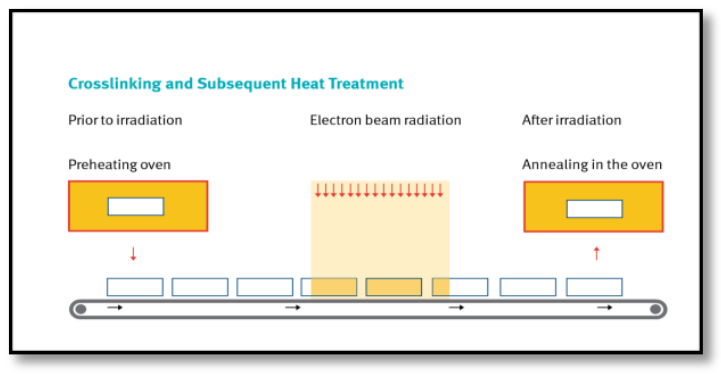

Fig. 3.6b: Cross Linking By Infrared Radiation

\section{Design Methodology}

Preliminary design of humidifier bottom plate is designed for aluminum as shown in figure. changes has to be made to the design as the previous design which is shown in the figure below is designed for aluminum but there are drastic changes in the properties so some design changes has to be made so that design holds good for XLPE and also mold designing considerations also should be taken in to consideration to meet the requirements as by the aluminum. 


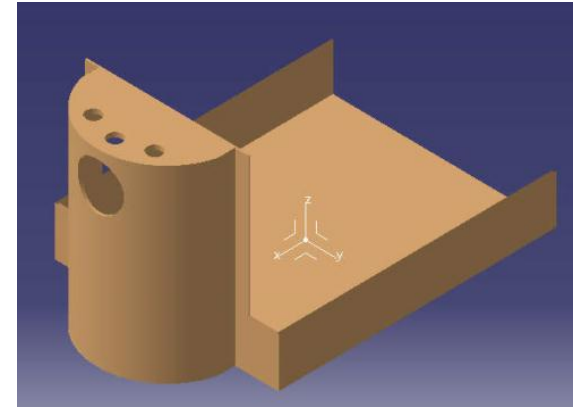

Fig. 4a: Humidifier isometric before design changes

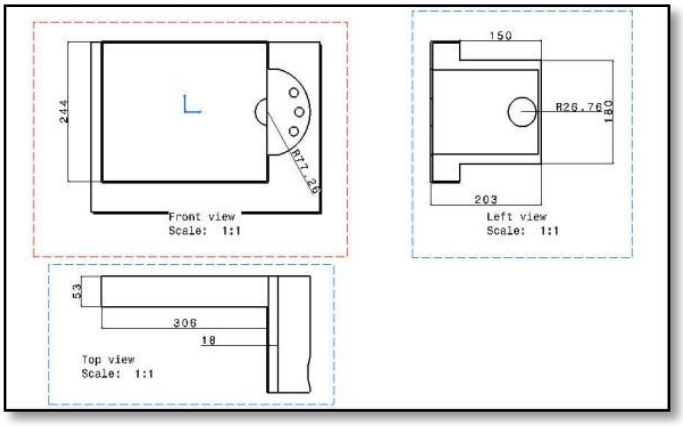

Fig. 4b: 2-D drawing of humidifier

The humidifier model is manufactured by using aluminium material below as shown in the fig.4c Drawback of the aluminium material weight is too high manufacturing feasibility is very difficult as size is too high.

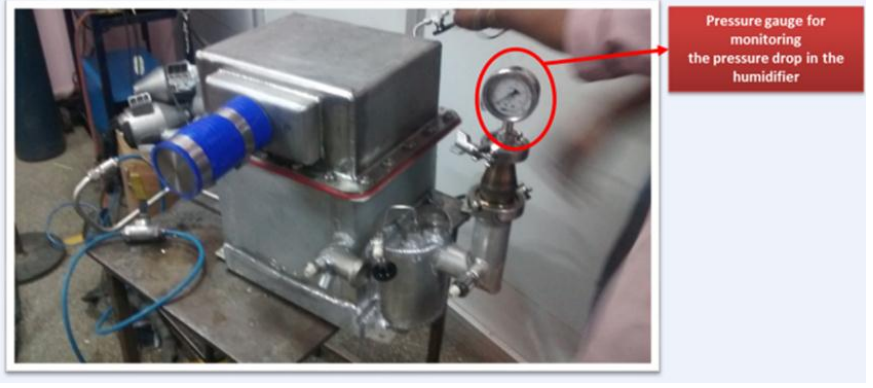

Fig. 4c: Humidifier (existing aluminium material) fabricated model

To impart strength to the bottom plate as it is going to be fabricated with XLPE ribs has to be given and also all the sharp corners has to be avoided and sudden increase in the height has to be avoided and also thickness has to be constant throughout the part these are minimum considerations to be considered before designing of any plastic parts based on these considerations some design changes are made to the humidifier bottom plate as shown in the figures below. These changes are done based on the plastic part design by lanxes.

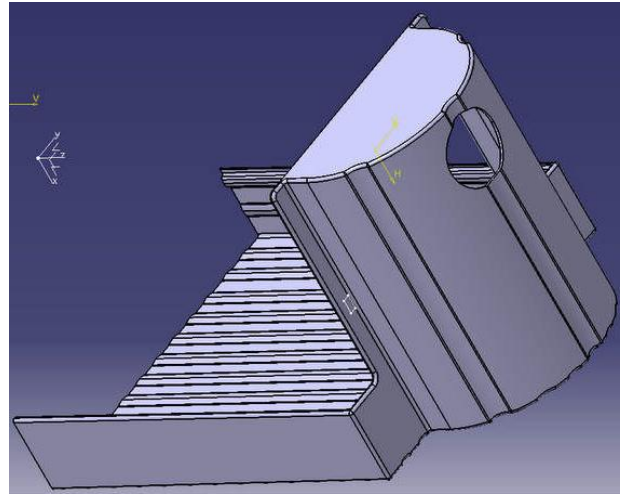

Fig. 4d: Isometric view of humidifier bottom plate after the design changes

In this model all the sharp corners has been rounded off to avoid concentrated stresses which may occur after molding due to improper cooling, ribs are given at regular intervals to all the faces in order to give sufficient strength to the plate. Ribs are used mainly for two purposes: to improve melt flow into a section, like corner or large boss and to increase flexural stiffness of the part. Designing thin walled plastic products one the most difficult problems is how to reach sufficient stiffness. The most economical way to increase stiffness may be using reinforcing ribs. Ribs should be placed on the moulds opening direction. Transverse ribs are also possible but making of them in the mould is not easy. For parts under bending, ribs should be placed perpendicular to the bending moment. For parts under torsion, ribs should be placed diagonally.

\subsection{Stuctural Analysis}

Structural analysis is carried out using ANSYS V14.5 module to check the maximum deformation and the stress on the bottom plate which is of $5 \mathrm{~mm}$ thickness due to working conditions. It is also subjected to thermal deformation and stresses as it is subjected to a temperature ranging from ambient to $90 \mathrm{o} \mathrm{C}$. The boundary conditions are: Pressure: $200 \mathrm{~Pa}(\max )$ applied normal to the internal faces of bottom plate as shown in figure 4.1a.

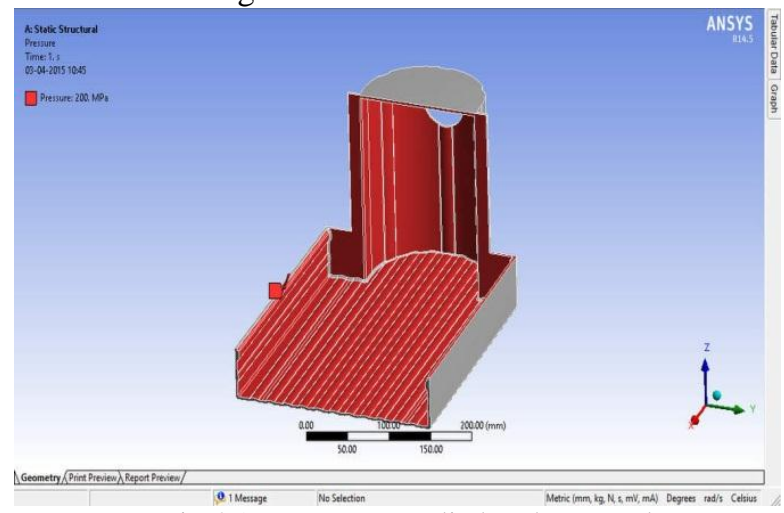

Fig 4.1a: Pressure applied on bottom plate 


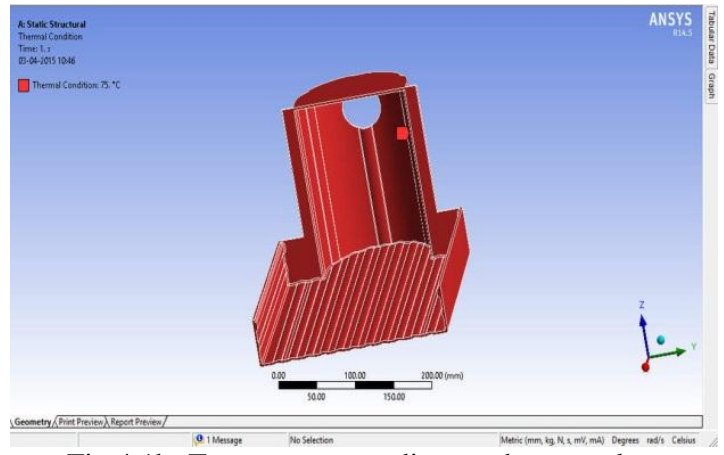

Fig 4.1b: Temperature gradient on bottom plate

Loads: a load of $70 \mathrm{~N}$ combined weight of core and top plate is acting on the top rib of side walls which is protruding inside such that the core can rest on it.

Temperature: a temperature gradient of $75^{\circ} \mathrm{c}$ is applied as the air supplied to the humidifier from compressor is around $60^{\circ} \mathrm{c}$.

\subsection{Mold Design}

UNIGRAPHICS is used for designing mold and the following figures $4.2 \mathrm{a} \& \mathrm{~b}$ show the preliminary mold design in which ring type runner is used, the mold is provided with six cooling channels.

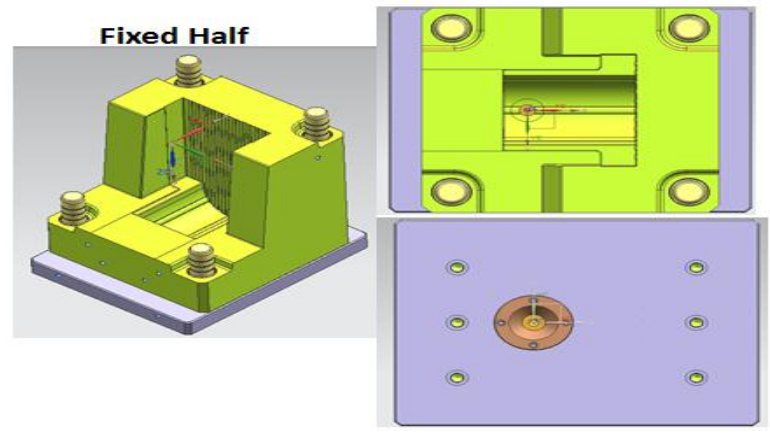

Fig 4.2a: MOLD design of bottom plate

\section{Moving Half}

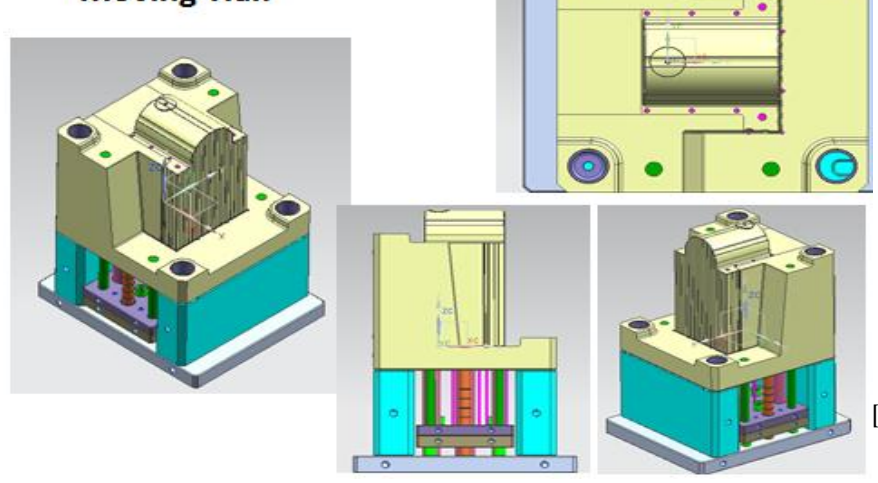

Fig 4.2b: MOLD design of bottom plate

\section{RESUlTS \& DisCUSSIONS}

Results obtained for bottom plate of $5 \mathrm{~mm}$ thickness using ANSYS solver for total deformation and Von-Moises stress (principle stress) as shown in figures $5.1 \& 5.2$.

\subsection{Deformation}

According to design calculations, maximum allowable deformation is $0.5 \mathrm{~mm}$ but the practical deformation is $0.525 \mathrm{~mm}$ which is $0.025 \mathrm{~mm}$ more than the allowable deformation. This can be overcome by high degree of cross linking at that point.

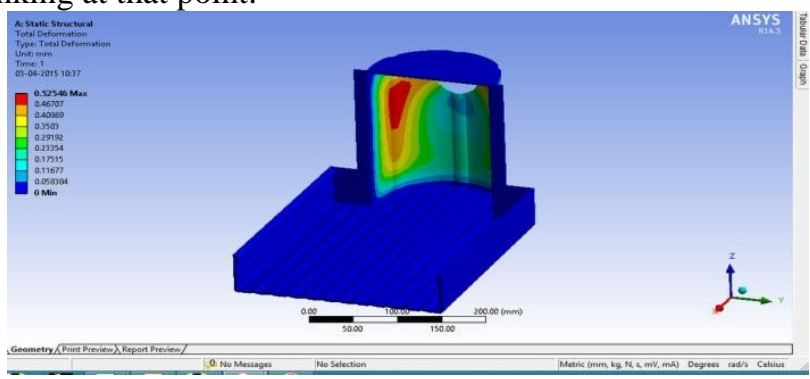

Fig 5.1: Deformation in bottom plate

5.2 Von-Moises Stress: (principle stress)

According to design calculations, maximum allowable stress is $25 \mathrm{MPa}$ and practical value is $10 \mathrm{MPa}$ which is well under allowable stress.

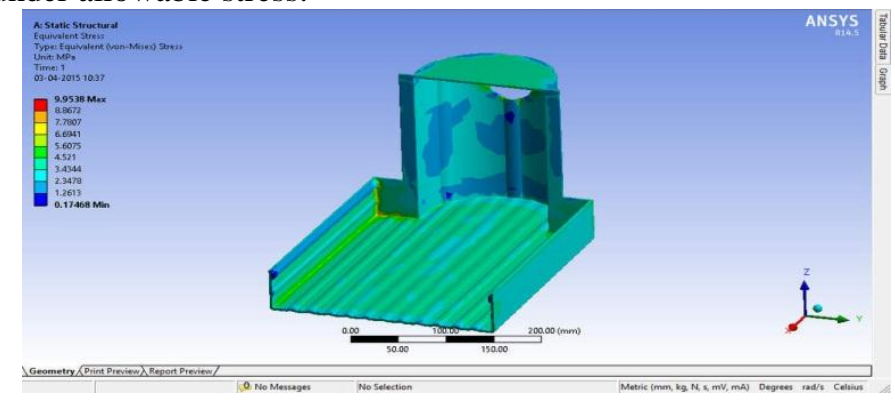

Fig 5.2: Stress concentration's in bottom plate

\section{CONCLUSION}

With the results obtained from both structural analyses cross-linked high density polyethylene with $5 \mathrm{~mm}$ thickness and ribs for structural stability can be replaced instead of aluminum which is denser and costlier. High density polyethylene without crosslinking will not serve the purpose as it melts at around $70^{\circ} \mathrm{C}$ which is the operating temperature of the humidifier crosslinking gives thermal stability by interlinking carbon molecules in the polymer.

\section{ACKNOWLEDGEMENT}

SERB, National Programme (NP-MICAV), DRDO Bhavan, New Delhi.

\section{REFERENCES}

[1] Dongmei Chen and Huei Pengl, "Modeling and Simulation of a PEM Fuel Cell Humidification System,"

Proceeding of the 2004 American Control Conference Boston, Massachusetts.

[2] David O. Kazmer, and Russell G.Speight, "Polymer injection molding technology for the next millennium,"

Journal of Injection Molding Technology, 1997.

[3] S M Tamboli, S T Mhaske \& D D Kale, "Cross linked polyethylene," Indian Journal Chemical technology, Vol. 11, Nov 2004, pp. 853-864, 2003.

[4] EG\&G Services. Fuel Cell Hand book. Parsons Inc., Morgantown, West Virginia, 2000. 
[5] D. Kazmer, "Plastics Manufacturing Systems Engineering," Carl Hanser Verlag, Munich, p. 502, 2009. http://dx.doi.org/10.3139/9783446430143

[6] "Plastics Processor Rankings," in: Plastics News, Crain Communications, Akron, OH, 2008.

[7] M. Holmes, " Global production capacities will increase," Plastic. Additives Compound, Vol 10 (3), pp 1-3, 2008. http://dx.doi.org/10.1016/S1464-391X(08)70061-8

[8] J.L. Spoormaker, "The role of failure analysis in establishing design rules for reliable plastic products," Microelectronics Reliability, Vol 35, pp 1275 $-1284,1995$. http://dx.doi.org/10.1016/0026-2714(95)99377-U

[9] L.J. George, J.W. Priest, G.T. Stevens Jr., "Proprinter design for manufacturability", Proceedings of the Fif teenth Annual Conference on Computers and Industrial Engineering, pp481 -485, 1993 http://dx.doi.org/10.1016/0360-8352(93)90325-r 